\title{
Strengthening Reinforced Concrete Beams with CFRP and GFRP
}

\author{
Mehmet Mustafa Önal \\ Vocational School, Ahi Evran University, 40100 Kırşehir, Turkey \\ Correspondence should be addressed to Mehmet Mustafa Önal; mmonal@ahievran.edu.tr
}

Received 18 November 2013; Revised 14 June 2014; Accepted 14 June 2014; Published 13 July 2014

Academic Editor: Osman Gencel

Copyright (C) 2014 Mehmet Mustafa Önal. This is an open access article distributed under the Creative Commons Attribution License, which permits unrestricted use, distribution, and reproduction in any medium, provided the original work is properly cited.

Concrete beams were strengthened by wrapping the shear edges of the beams twice at $45^{\circ}$ in opposite directions by either carbon fiber reinforced polymer (CFRP) or glass fiber reinforced polymer (GFRP). The study included 3 CFRP wrapped beams, 3 GFRP wrapped beams, and 3 control beams, all of which were $150 \times 250 \times 2200 \mathrm{~mm}$ and manufactured with C20 concrete and S420a structural steel at the Gazi University Technical Education Faculty labs, Turkey. Samples in molds were cured by watering in the open air for 21 days. Four-point bending tests were made on the beam test specimens and the data were collected. Data were evaluated in terms of load displacement, bearing strength, ductility, and energy consumption. In the CFRP and GFRP reinforced beams, compared to controls, $38 \%$ and $42 \%$, respectively, strength increase was observed. In all beams, failure-flexural stress occurred in the center as expected. Most cracking was observed in the flexural region 4. A comparison of CFRP and GFRP materials reveals that GFRP enforced parts absorb more energy. Both materials yielded successful results. Thicker epoxy application in both CFRP and GFRP beams was considered to be effective in preventing break-ups.

\section{Introduction}

Because of the increasing population of cities, there is a very high demand for apartments. Moreover, due to the ongoing trend toward moving to the city, there is a sharp increase in city populations and therefore new residential areas are needed to meet the high demand. Along with the population boom, the need for more public buildings, such as social facilities and schools, has arisen. Therefore, in order to use the national resources optimally, ways to repair and strengthen damaged buildings need to be explored.

The term "repairing" involves alterations in a functionally or visually damaged building to make it like new. "Strengthening" involves alterations in a building to increase its loadcarrying capacity, rigidity, ductility, and stability. This study focuses on strengthening. Stirrup not placed according to the spacing values given in the construction plan, insufficient longitudinal main reinforcements, insufficiently anchored reinforcements, casual placement of reinforcements, collapse of non-load-bearing walls and chimneys, and using low quality concrete are some of the reasons resulting in the need for strengthening [1].
There is a need for such a strengthening method that, during the strengthening process, residents of the building do not need to empty the building; neighboring buildings are not affected by strengthening, and strengthening is completed in a short period of time. Moreover, by this particular strengthening method, the building is expected to be stronger and well-qualified in terms of earthquake resistance regulations. In addition, this particular method must be consistent with the current aesthetic condition and also it must be affordable.

Norris et al. strengthened concrete beams in tensile regions with FRP and analytically and experimentally studied the results. They found that CFRPs applied vertically to cracks increased the endurance and rigidity. They reported that, because of tension accumulation, brittle fractures were observed [2].

Kachlakev and McCurry applied 2 different reinforcement methods in dislocation regions of beams: textile application to the shear region entirely and partially. They suggested a cost-effective strengthening method with this study [3].

Yang and Nanni strengthened full-scale beams with FRP plates against bending and shear. Through 4-point 


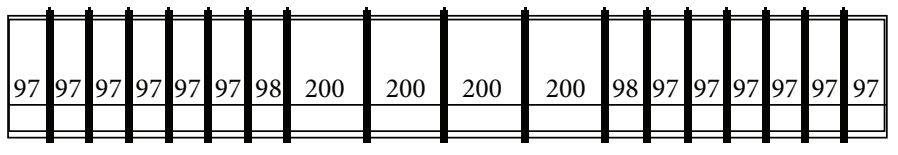

(a)
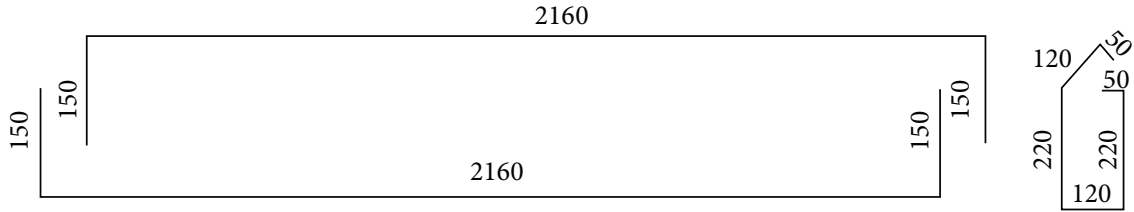

(b)

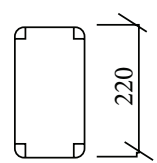

$\nvdash 120\rfloor$

Figure 1: Reinforcement details of the experimental beams [12].

bending experiments, load reflection and tension values were determined. In all samples, a $150 \%$ increase in strength was observed [4].

Alkan investigated the process of corner rounding in FRP strengthening. In circular beams, FRP capacity reached $67 \%$. The author highlighted the remarkable effect of corner rounding [5].

Perera et al. applied the same strengthening method to $60 \times 120 \times 500 \mathrm{~mm}$ beam samples. The CFRP reinforced samples were exposed to the 3-point bending test. CFRP was wrapped as a single layer around the beams within the entire tensile region and half of the sides. Results showed that the reinforced beams carried $80 \%$ more load [6].

Maalej and Leong studied the bonding behavior of CFRP and concrete blocks and discussed it in terms of analytical results. Adherence surfaces of various samples were exposed to test and the damaged samples were examined with the finite elements model. In general, they reported a good correlation between computational solutions and experimental results [7].

\section{Materials and Methods}

2.1. Materials. Nine $150 \times 250 \times 2200 \mathrm{~mm}$ samples were prepared with C20 and S240 materials. Deformed $\varnothing 8$ and $\varnothing 12$ bars were used. In both $1 / 3$ shear regions, $50 \%$ more reinforcement was used. Table 1 shows the strengthening plan and Figure 1 depicts the reinforcement details.

2.1.1. Mechanical Properties of the Mold Materials Used in the Study. Poplar wood $(30 \mathrm{~mm})$ was used as the mold material in the study. Nine $150 \times 250 \times 2200 \mathrm{~mm}$ molds were constructed and prepared with form oil ready to use.

\subsubsection{Mechanical Properties of the Concrete Used in the Study.} C20 concrete used in the study was obtained from a readymixed concrete plant. The properties of the C20 concrete: cement type: CEM I 32.5, slump value $=10 \mathrm{~cm}$, maximum aggregate size $=16 \mathrm{~mm}$, water $/$ cement ratio $=0.58$, water weight $=228 \mathrm{~kg}$, and cement weight $=393 \mathrm{~kg}$. Concretes placed in molds were compressed using a vibrator obtained
TABLE 1: Strengthening plan [12].

\begin{tabular}{ll}
\hline $\begin{array}{l}\text { The number of concrete } \\
\text { beams used in the } \\
\text { experiments and their } \\
\text { dimensions }(\mathrm{mm})\end{array}$ & Comment \\
\hline $\begin{array}{l}3 \text { units } \\
150 \times 250 \times 2200\end{array}$ & 3 control beams (group 1) \\
\hline & $\begin{array}{l}3 \text { concrete beams were strengthened } \\
\text { with CFRP in the shear region } \\
\text { (group 2) } \\
\text { (both shear regions (1/3) were } \\
\text { wrapped at 45 in both directions) }\end{array}$ \\
\hline $\begin{array}{l}3 \text { concrete beams were strengthened } \\
\text { with GFRP in the shear region } \\
\text { (group 2) } \\
\text { (both shear regions (1/3) were } \\
\text { wrapped at 45 in both directions) }\end{array}$ \\
\hline
\end{tabular}

from the construction laboratory. Samples in molds were cured by watering in the open air for 21 days. Sample concrete cylinders were tested 29 days after the production date and load and stress values are presented in Table 2.

2.1.3. Mechanical Properties of the Epoxy Mixture Used in the Study. Sikadur $330(1.31 \mathrm{~kg} / \mathrm{L})$ with A and B components, which is stiff like dough, was used. A and B components were stirred individually in different containers for 3 min first and then A was poured onto B and they were mixed together. The mixture was applied on the surface with a plasterer's trowel and a flat scraper. The amount of adhesive was kept at $2 \mathrm{~kg} / \mathrm{m}^{2}$. For attaching the second coat on CFRPs, epoxy was applied 1 day later. In order to avoid external effects, closing procedure was performed 1 day later. Temperature and the amount of adhesive used were carefully monitored during epoxy applications [8].

2.1.4. Mechanical Properties of the CFRP Used in the Study. CFRP, which is made of carbon fiber, was uniaxial Sika Wrap with $230 \mathrm{~g} / \mathrm{m}^{2}$ density, $0.13 \mathrm{~mm}$ thickness, and received as $0.60 \times 50 \mathrm{~m}$ rolls [8]. 
TABLE 2: Detailed results of the sample concrete cylinders.

\begin{tabular}{lcccc}
\hline C20 samples & Cylinder diameter $(\mathrm{mm})$ & Axial load $(\mathrm{KN})$ & Section $\left(\mathrm{mm}^{2}\right)$ & Axial compressive stress $\left(\mathrm{KN} / \mathrm{mm}^{2}\right)$ \\
\hline 1 & 150 & 64 & 17663 & 0.0038 \\
2 & 150 & 63 & 17663 & 0.0039 \\
3 & 150 & 62 & 17663 & 0.0036 \\
\hline
\end{tabular}

TABLE 3: Mechanical properties of the sample beams.

\begin{tabular}{lcccccccc}
\hline Number & Sample & Type & Quantity & Surface $\left(\mathrm{mm}^{2}\right)$ & Reinforcement ratio & $f_{\text {ck }}\left(\mathrm{N} / \mathrm{mm}^{2}\right)$ & $f_{\text {yk }}\left(\mathrm{N} / \mathrm{mm}^{2}\right)$ & $f_{\text {su }}\left(\mathrm{N} / \mathrm{mm}^{2}\right)$ \\
\hline 1 & K101 & S420a & $2 ø 12$ & 37500 & 0.00602 & 0.0036 & 44.93 & 68 \\
2 & K102 & S420a & $2 ø 12$ & 37500 & 0.00602 & 0.0036 & 44.93 & 68 \\
3 & K103 & S420a & $2 ø 12$ & 37500 & 0.00602 & 0.0036 & 44.93 & 63 \\
4 & KG201 & S420a & $2 ø 12$ & 37500 & 0.00602 & 0.0036 & 44.93 & 44.93 \\
5 & KG202 & S420a & $2 ø 12$ & 37500 & 0.00602 & 0.0036 & 44.93 \\
6 & KG203 & S420a & $2 ø 12$ & 37500 & 0.00602 & 0.0036 & 68 \\
7 & KG301 & S420a & $2 ø 12$ & 37500 & 0.00602 & 0.0036 & 44.93 \\
8 & KG302 & S420a & $2 ø 12$ & 37500 & 0.00602 & 0.0036 & 44.93 & 68 \\
9 & KG303 & S420a & $2 ø 12$ & 37500 & 0.00602 & 0.0036 & 44.93 & 68 \\
\hline
\end{tabular}

$f_{\mathrm{ck}}$ : concrete cylinder compressive strength, $f_{\mathrm{yk}}$ : steel yield strength, and $f_{\mathrm{su}}$ : steel tensile strength.

2.1.5. Mechanical Properties of GFRP Used in the Study. GFRP, which is made of glass fiber, was uniaxial Sika Wrap $430 \mathrm{G}$ with $430 \mathrm{~g} / \mathrm{m}^{2}$ density and received as $0.60 \times 50 \mathrm{~m}$ rolls. Compressive strength of GFRP was $3300-4500 \mathrm{mpa}$ and elongation at break was 0.048 [8].

\subsubsection{Reinforcement Mechanical Properties and Symbols of the} Sample Concrete Beams. Mechanical properties of the sample concrete beams manufactured for strengthening purposes are presented in Table 3.

2.2. Methods. A total of 9 beams $(150 \times 250 \times 2200 \mathrm{~mm})$ were manufactured with C20 concrete and S420a structural steel. Then, the beams were strengthened with either CFRP (3 beams) or GFRP (3 beams) by wrapping them twice at the shear zone at $45^{\circ}$ opposing directions. Another set of 3 beams was used as controls. Entire tensile stress zone of the shear region was strengthened by wrapping. A total of 6 displacement transducers were set up to determine the cracks in 6 different zones: 2 spots on each side of the beams symmetrically and 2 spots in the tensile and pressure zones. In the sample beams, which were subjected to loading on 4 different points, the effective span was taken as $2000 \mathrm{~mm}$. Loading and displacement values were also determined.

2.2.1. Types of Strengthening Materials and Methods. Types of strengthening materials and methods are presented in Table 4 .

2.2.2. Preparation of the Beams. Sample beams were transferred into the laboratory 30 days after manufacturing. Three control samples were set aside and the remaining 6 beams were processed for surface preparation before strengthening. Sides and the bottom of the beams were ground to remove the uneven parts caused by the mould. Dust was removed
TABLE 4: Strengthening of the sample beams.

\begin{tabular}{lll}
\hline \multicolumn{2}{l}{ NumberSamples } & Types of strengthening material and method \\
\hline 1 & K101 & Control \\
2 & K102 & Control \\
3 & K103 & Control \\
4 & KC201 & CFRP $45^{\circ}$ double-wrapped in opposite directions \\
5 & KC202 & CFRP $45^{\circ}$ double-wrapped opposite directions \\
6 & KC203 & CFRP $45^{\circ}$ double-wrapped opposite directions \\
7 & KG301 & GFRP $45^{\circ}$ double-wrapped opposite directions \\
8 & KG302 & GFRP $45^{\circ}$ double-wrapped opposite directions \\
9 & KG303 & GFRP $45^{\circ}$ double-wrapped opposite directions \\
\hline
\end{tabular}

by pressurized water. Preparation of experimental beams is shown in Figure 2.

2.2.3. Strengthening of the Beams by Affixing $45^{\circ}$ CFRP or GFRP. The first 3 samples were set aside as controls and they were not strengthened. Tensile region of the beams (K101, K102, and K103; see Figure 3) were prepared for the experiment by removing all moving particles on the surface. One-third of each beam on both ends was determined as the strengthening area. Epoxy $\left(2 \mathrm{~kg} / \mathrm{m}^{2}\right)$ was applied on the surface of the strengthening area. CFRP on 3 beams and GFRP on the other 3 beams were affixed at $45^{\circ}$ without leaving any air pocket. In order to remove air pockets in between the textile and the beam, a rolling cylinder was used. One day later, the same amount of epoxy was applied to CFRP. One week later, assembly cubes for strain gauge were attached with epoxy on the spots where crack determination will be performed. Ten days after this process, loading experiments were performed. CFRP and GFRP application on concrete beams is shown in Figure 3. 


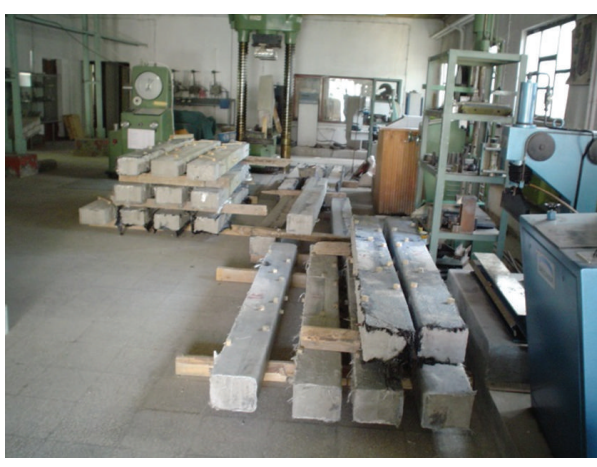

(a)

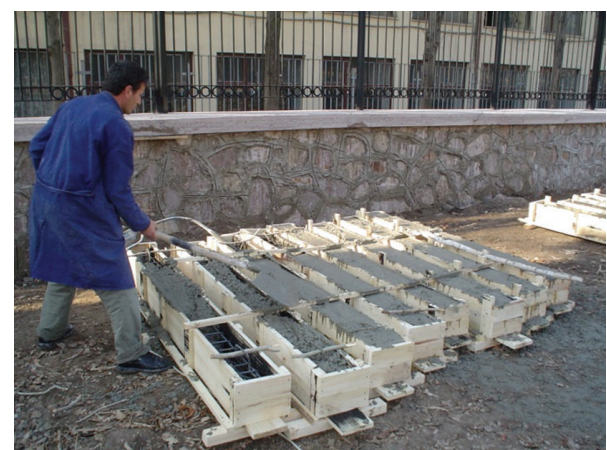

(b)

Figure 2: Preparation of experimental beams.

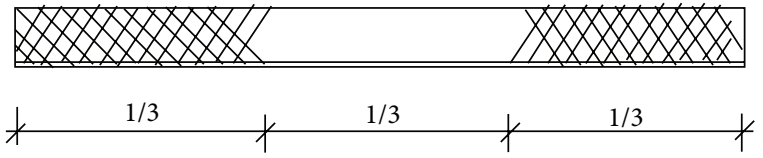

FIGURE 3: CFRP and GFRP application on concrete beams.

2.2.4. Experimental Setup. Experiments were carried with a loading device "Brand Model" at the Mechanics Laboratory of the Construction Education Department at Gazi University in Ankara. The device has 2 support points on a cart moving along a rail. The distance between these 2 supports was set to $2000 \mathrm{~mm}$ and one of which was fixed.

Four-point loading was applied on the top of the beams on 2 points. The distance between the loading zones was $660 \mathrm{~mm}$. Metal plates with $10 \mathrm{~mm}$ thickness were obtained to be used on the zones where the loading was applied. A magnetized apparatus to which a linear variable differential transformer (LVDT) was attached was placed on top of the beams. Strain gauges were attached on each beam at the same 6 points. Data were recorded every 5 seconds with a data collection system through 8 channels: 6 crack, 1 displacement, and 1 loading data.

Loading was applied on 2 points on top of the beam and on 2 points where the support points are located at the bottom. One of the support points was fixed and the other was movable. Crack formation was observed using the data collected on 6 points on each beam. LVDT measuring displacement with $0.001 \mathrm{~mm}$ accuracy was placed in the middle of each beam. Recording was monitored on a data logger digital screen. Strain gauge device and LVDT are shown in Figure 4 and scheme of the loading mechanism is shown in Figure 5.

\section{Results and Discussion}

The data obtained in the present study are discussed in terms of load carrying capacity, load-displacement, tensile, and energy consumption capacity.

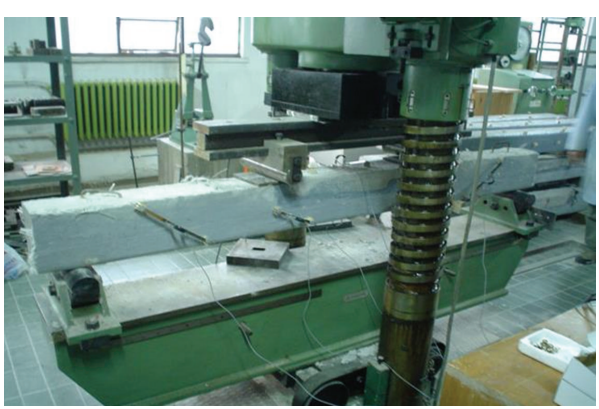

FIGURE 4: Strain gauge device and LVDT.

3.1. Load Carrying Capacity of the Concrete Beams. If loading is in low levels in a concrete beam prone to deflect, there may not exist any cracking in tensile regions. In that case, reinforcement and concrete carry the load on the tensile section altogether. However, because it would not be economical, except in pretension beams, to maintain all tensile sections in a quality preventing cracking, cracks occur in the tensile region of concrete materials [9].

Concrete between cracks may help the tensile a little bit. However, because this help is in a negligible amount, in a cracked section, all load carrying is assumed to be maintained by reinforcement. One thing that is for sure is that reinforcement cannot prevent cracking. The main function of reinforcement is to satisfy the tensile stress and keep cracks at minimum in size [10].

According to the Turkish Standards TS500 [11], in finding the concrete compressive strength in its compression zone, tensile stress distribution is converted to an equivalent rectangular by multiplying the $f_{\mathrm{ck}}$ value by 0.85 . It is very useful to know the behavior of deflecting beams that are exposed to loading before calculating their load carrying capacity. The first cracks occurring in the tensile region are a result of the reach of the unit elongation of the outer tensile fiber to the upper tensile limit of the concrete. Crack moments of nonreinforced beams are assumed to be equal to their crushing moment [11]. 


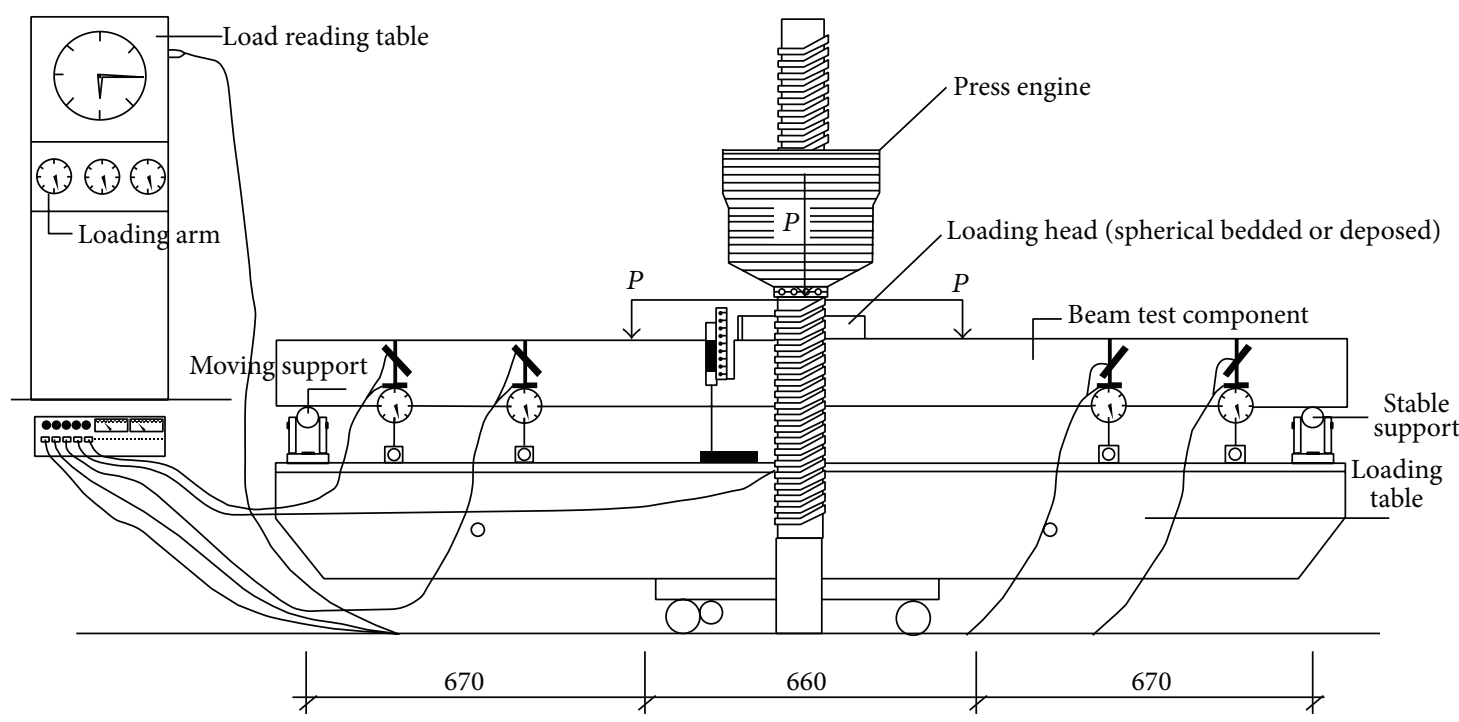

FIGURE 5: Scheme of the loading mechanism.

TABLE 5: Displacement values of each beam against the maximum load.

\begin{tabular}{lcc}
\hline Sample beams & The maximum load $(\mathrm{N})$ & Displacement $(\mathrm{mm})$ \\
\hline K101 & 99000 & 32 \\
K102 & 92600 & 49 \\
K103 & 95900 & 55 \\
KC301 & 116400 & 26 \\
KC302 & 119200 & 30 \\
KC303 & 117500 & 12 \\
KG301 & 122700 & 35 \\
KG302 & 124600 & 28 \\
KG303 & 121000 & 44 \\
\hline
\end{tabular}

3.2. Load-Displacement Charts. Displacement values were recorded exactly at the center of the sample beams by LVDT at the same speed and by resetting the electronic meters each time. Displacement values of all sample beams against the maximum loading are presented in Table 5.

As a result of reinforcing, a reduction in displacement was observed. While there was a $35 \%$ increase in the strength of the beams with CFRP, there was $41 \%$ decrease in displacement. Furthermore, a $43 \%$ increase was observed in the strength of GFRP beams and 53.6\% decrease in displacement.

Load-displacement chart of the sample beams diagrams K101, K102, and K103 is presented in Figure 6, loaddisplacement chart of the strengthened sample beams diagrams KC201, KC202, and KC203 is presented in Figure 7, load-displacement chart of the strengthened sample beams diagrams KG301, KG302, and KG303 is presented in Figure 8, respectively.

3.3. Ductility Rates of the Beams. Ductility rate was calculated by the load-displacement relationship. The deformation value at the point where the vertical line crosses the $85 \%$

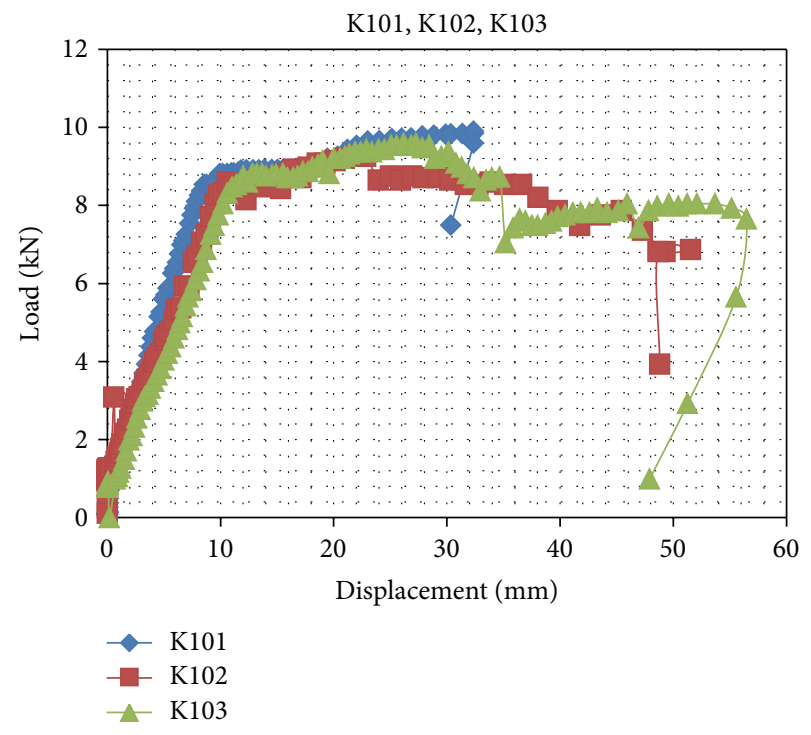

FIGURE 6: Load-displacement chart of the control sample beam.

of the monolithic beam strength of the load-displacement curve was determined. Ductility rate is defined as the value determined by dividing this deformation value by its creep deformation value. There are 2 types of ductility in reinforced concrete load bearing systems: curvature ductility and displacement ductility [10].

Although it is possible to use the moment ductility relationship to calculate ductility, load-displacement relationship was used instead.

3.4. Energy Consumption in the Sample Beams. In calculating the energy consumption of beams, load-displacement curves are used. The area under the curve yields the energy consumption [10]. 
TABLE 6: Shear cracks against the maximum load in sample beams.

\begin{tabular}{lccc}
\hline Sample beams & Maximum load $(\mathrm{N})$ & Strain gauge 2 $(\mathrm{mm})$ & Strain gauge 5 $(\mathrm{mm})$ \\
\hline K101 & 99000 & 28 & 0.15 \\
K102 & 92600 & 28 & 0.13 \\
K103 & 95900 & 20 & 0.24 \\
KC201 & 116400 & 0.57 & 0.16 \\
KC202 & 119200 & 0.50 & 0.48 \\
KC203 & 117500 & 0.59 & 0.80 \\
KG301 & 122700 & 0.45 & 0.38 \\
KG302 & 124600 & 0.30 & 0.25 \\
KG303 & 121000 & 0.10 & 0.26 \\
\hline
\end{tabular}

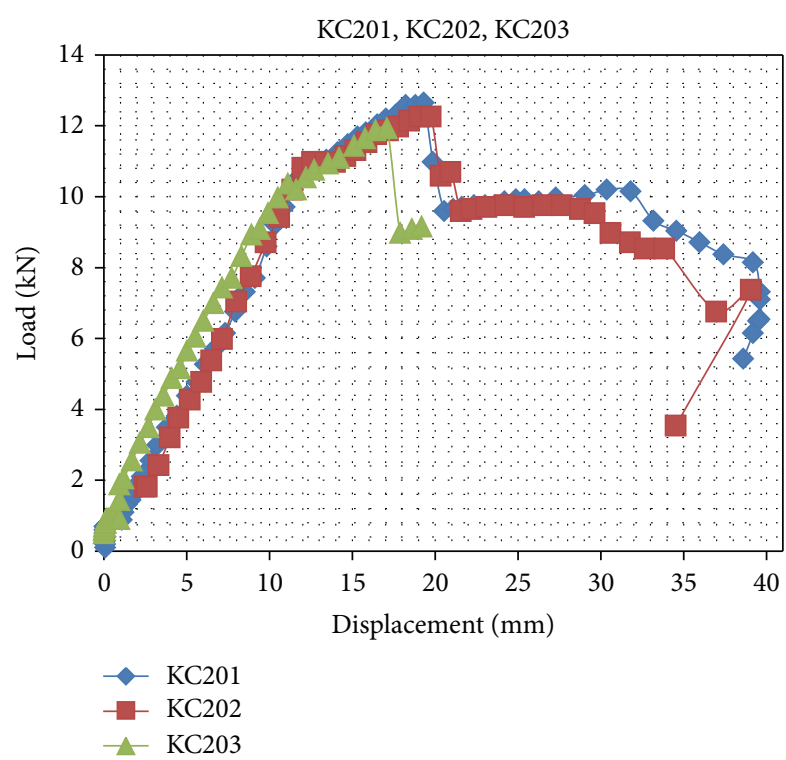

FIGURE 7: Load-displacement chart of the sample beam strengthened with CFRP.

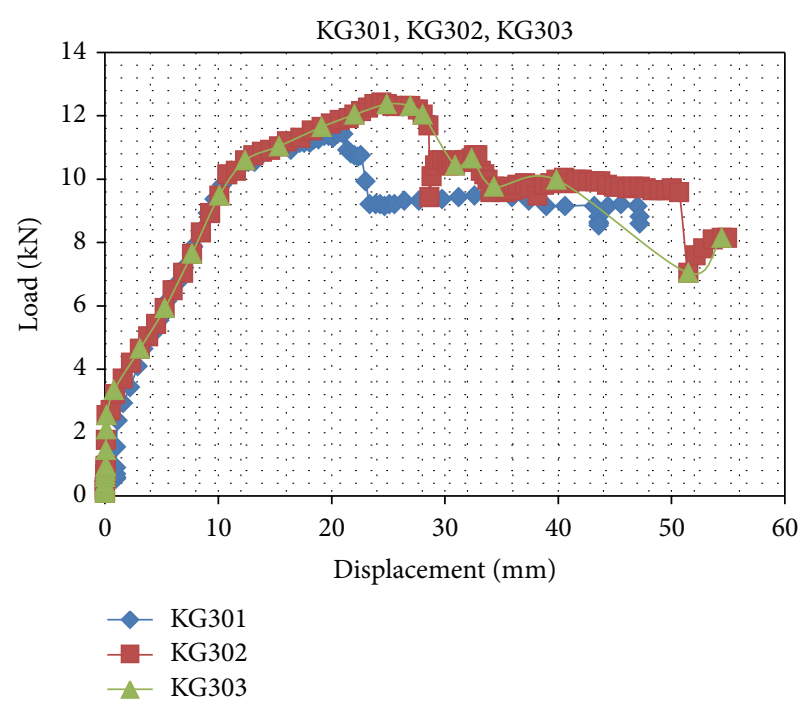

FIGURE 8: Load-displacement chart of the sample beam strengthened with GFRP.
TABLE 7: Flexural cracks against the maximum load in sample beams.

\begin{tabular}{lcc}
\hline Sample beams & Maximum load $(\mathrm{N})$ & Strain gauge $4(\mathrm{~mm})$ \\
\hline K101 & 99000 & 62 \\
K102 & 92600 & 68 \\
K103 & 95900 & 74 \\
KC201 & 116400 & 0.68 \\
KC202 & 119200 & 0.71 \\
KC203 & 117500 & 0.66 \\
KG301 & 122700 & 0.14 \\
KG302 & 124600 & 0.21 \\
KG303 & 121000 & 0.22 \\
\hline
\end{tabular}

Energy consumption rates of all beams were calculated using the area under the load-displacement curves. A certain amount of energy is spent as conversion to deformation. The amount of convertible energy is directly proportional with the length of the plastic region. As energy is the ability to do work, the amount of energy consumed has importance. In the load-displacement curve, energy consumption was found at the point where the maximum loading occurred.

3.5. Crack Loading Values. The data collected through 4 strain gauges placed on the shear region of the beams are presented in Table 6 and flexural cracks against the greatest load of beam samples presented in Table 7 .

Shear cracks in the control beams were found as $28 \mathrm{~mm}$ in gauge 2 and $0.15 \mathrm{~mm}$ in 5 . There was a $100 \%$ crack reduction in the CFRP sample in 2 while there was a $295 \%$ crack increase in 5. Cracks fell by $87 \%$ in the GFRP beams in gauge 2 and increased by $119 \%$ in 5 . Also, by the help of reinforcement densification, shear region in region 2 was considerably strengthened. Shear effect was observed as more effective in region 5 .

The changes in the tensile regions of the beams are as given above. The average change in the control beams against the maximum load was found as $70 \mathrm{~mm}$. Cracks were reduced by $71 \%$ in the CFRP beams and $139 \%$ in GFRP beams. Improvements in this region are thought to improve the beam rigidity. 
TABLE 8: Energy consumption capacity of the beams.

\begin{tabular}{lccc}
\hline Sample beams & Max. Pu $(\mathrm{kN})$ & Central failure $(\mathrm{mm})$ & Energy consumption capacity $(\mathrm{kNmm})$ \\
\hline K101 & 99000 & 45.44 & 942.216 \\
K102 & 92600 & 41.13 & 985.482 \\
K103 & 95900 & 50.24 & 1214.443 \\
KC201 & 116400 & 35.28 & 1416.874 \\
KC202 & 119200 & 29.54 & 1358.371 \\
KC203 & 117500 & 31.50 & 1376.716 \\
KG301 & 122700 & 37.63 & 1466.931 \\
KG302 & 124600 & 29.40 & 1147.853 \\
KG303 & 121000 & 33.74 & 1255.316 \\
\hline
\end{tabular}

$\mathrm{Pu}$ : collapse load according to the steel yield load.

3.6. Energy Consumption Values. The amount of energy spent was calculated by locating the yield and failure moments. The curves obtained for all the beams and the areas under these curves are presented in Table 8 . These values are considered in relation with the displacement and load values. Compared to the control beams, there was a $32 \%$ failure reduction in the CFRP beams while there was a $16.3 \%$ increase in energy consumption. Among the GFRP beams, 27\% failure decrease and $22 \%$ energy consumption increase were observed.

\section{Conclusions}

Strength increasing of the beams strengthened with CFRP was $84 \%$ and the displacement reduction was found to be $39.5 \%$. Strength increasing of the beams strengthened with GFRP was $45 \%$, and the displacement reduction was found to be $53.6 \%$.

In reinforced concrete beams strengthened with CFRP, there occurred a failure reduction by $29 \%$ as compared to control beams but energy consumption was increased $14.5 \%$. In reinforced concrete beams specimens strengthened with GFRP, there occurred a failure reduction by $25 \%$ as compared to control beams specimens but energy consumption was increased $18 \%$.

With increasing loading, the strengthened beams collapsed as shear fracture. In the samples, strength increased to some degree, but no increase was observed in terms of ductility and energy consumption. An apparent increase was observed in the bending strength. In the CFRP and GFRP reinforced beams, compared to controls, $38 \%$ and $42 \%$, respectively, strength increase was observed.

GFRP beams were observed to break apart, as layers, easier than the CFRP beams. In all beams, failure-flexural stress occurred in the center as expected.

Most cracking was observed in the flexural region 4 . In the control beams, crack size was observed as $0.25 \mathrm{~mm}$ in the secondary shear regions. On the other hand, in the same region, the crack size was $0.54 \mathrm{~mm}$ in CFRP beams and $0.33 \mathrm{~mm}$ in GFRP beams.

Cracking values recorded at the center and bottom of beams, where the maximum flexural and tensile stress were observed, were $0.68 \mathrm{~mm}$ in the control beams, and $0.71 \mathrm{~mm}$ and $0.14 \mathrm{~mm}$ in the CFRP and GFRP beams, respectively.
Displacement value of the control beams was observed as $45 \mathrm{~mm}$ and $21 \mathrm{~mm}$ and $29 \mathrm{~mm}$ in the CFRP and GFRP beams, respectively.

A comparison of CFRP and GFRP materials reveals that GFRP enforced parts absorb more energy. Both materials yielded successful results. In the present applications, it was observed that corner rounding was successful and that double wrapping in 2 opposing directions is not more effective than single wrapping compared to the literature. Thicker epoxy application in both CFRP and GFRP beams was considered to be effective in preventing break-ups. Because this material is lightweight, noncorroding, flexible, and available in large sizes, it is superior. Moreover, in case of fatigue, because of its elastic behavior, it has low ductility. Therefore, it is useful in temporary reinforcement applications.

\section{Conflict of Interests}

The author declares that there is no conflict of interests regarding the publication of this paper.

\section{References}

[1] M. M. Önal, An experimental research of the damaged rectangular cross-section beams repair by the method of coating [Ph.D. thesis], Gazi University Institute of Science, Ankara, Turkey, 2002.

[2] T. Norris, M. Lean, H. Saadetmenesh, and M. R. Ehsani, "Analytical and experimental studies on strengthening of reinforced concrete beams with carbon FRP," Journal of Structural Engineering, Arizona, p. 903, 1997.

[3] D. Kachlakev and D. D. McCurry, "Behavior of full-scale reinforced concrete beams retrofitted for shear and flexural with FRP laminates," Composites B: Engineering, vol. 31, no. 6-7, pp. 445-452, 2000.

[4] X. B. Yang and A. Nanni, "Cocrete beams strengthened with misaligned CFRP laminates," in Fibre-Reinforsed Plastics for Reinforsed Concrete Structures-FRPRCS-5, vol. 1, pp. 79-85, University of Cambridge, 2001.

[5] A. M. Alkan, Structure strengthening and improving by using polymer matrix composite [M.S. thesis], Sakarya University, Institute of Science and Technology, Sakarya, Turkey, 2002.

[6] R. Perera, A. Recuero, A. de Diego, and C. López, "Adherence analysis of fiber-reinforced polymer strengthened RC beams," 
Computers and Structures, vol. 82, no. 23-26, pp. 1865-1873, 2004.

[7] M. Maalej and K. S. Leong, "Effect of beam size and FRP thickness on interfacial shear stress concentration and failure mode of FRP-strengthened beams," Composites Science and Technology, vol. 65, no. 7-8, pp. 1148-1158, 2005.

[8] Teknomed Engineering Ltd, Quake Wrap Product Catalog, Istanbul, Turkey, 2000.

[9] U. Ersoy and G. Özcebe, Basic Principles of Reinforced Concrete TS-500-2000 and Calculated in Accordance with Regulations of the Turkish Earthquake, Bizim Office Publications, Ankara, Turkey, 2001.

[10] E. Atımtay, Regulations with Explanations and Examples on Reinforced Concrete Structures to Be Built in Disaster Areas, Bizim Office Publications, Ankara, Turkey, 2000.

[11] TS 500, "Calculations and construction rules of reinforced concrete structures," Turkish Standards.

[12] M. Önal, "Repair and strengthening of damaged beams in reinforced concrete structures," Scientific Research Projects 38/2004-01, Department of Gazi University, 2006. 

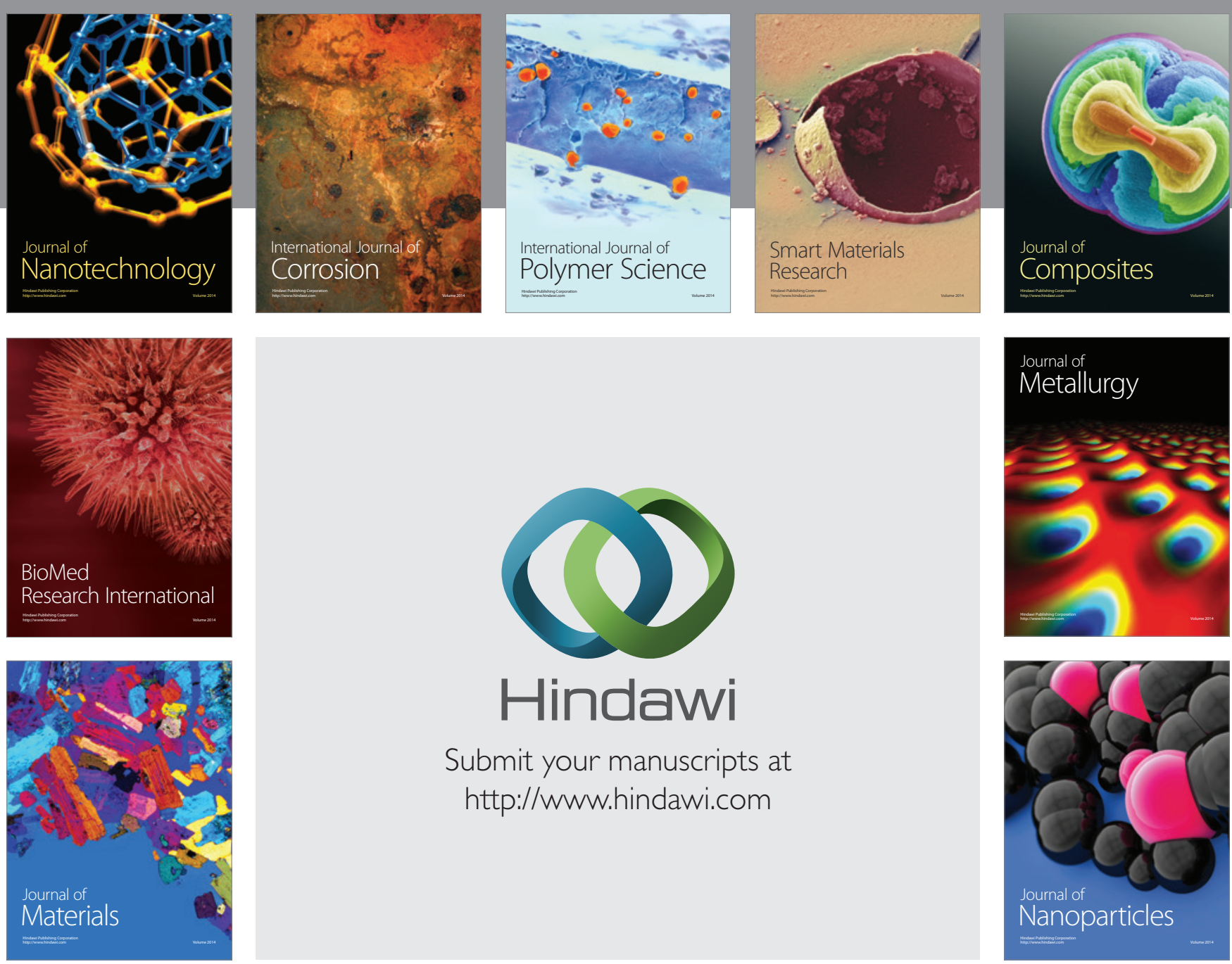

Submit your manuscripts at http://www.hindawi.com
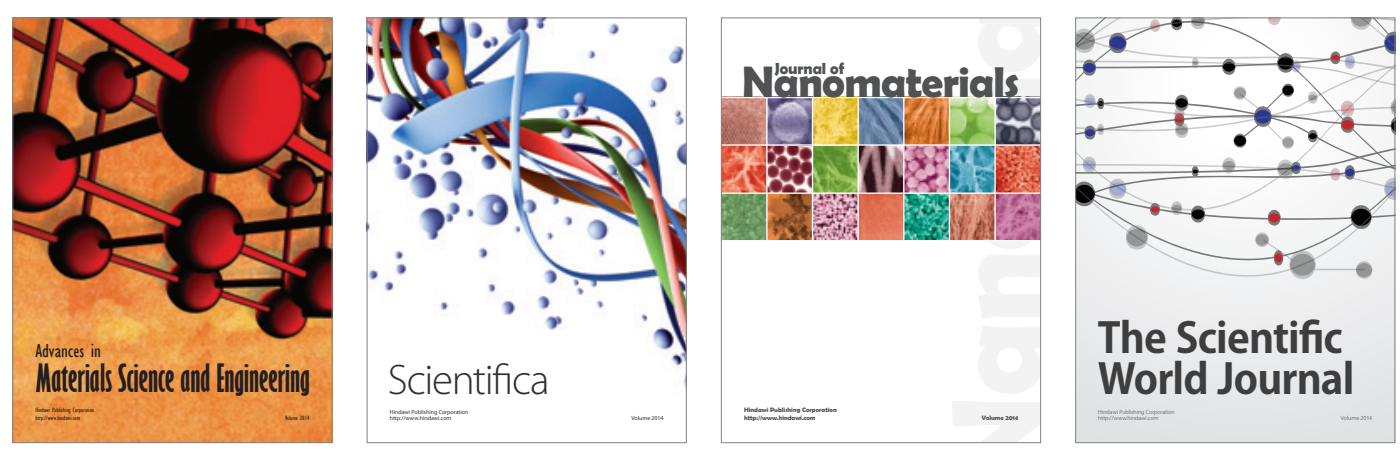

\section{The Scientific World Journal}
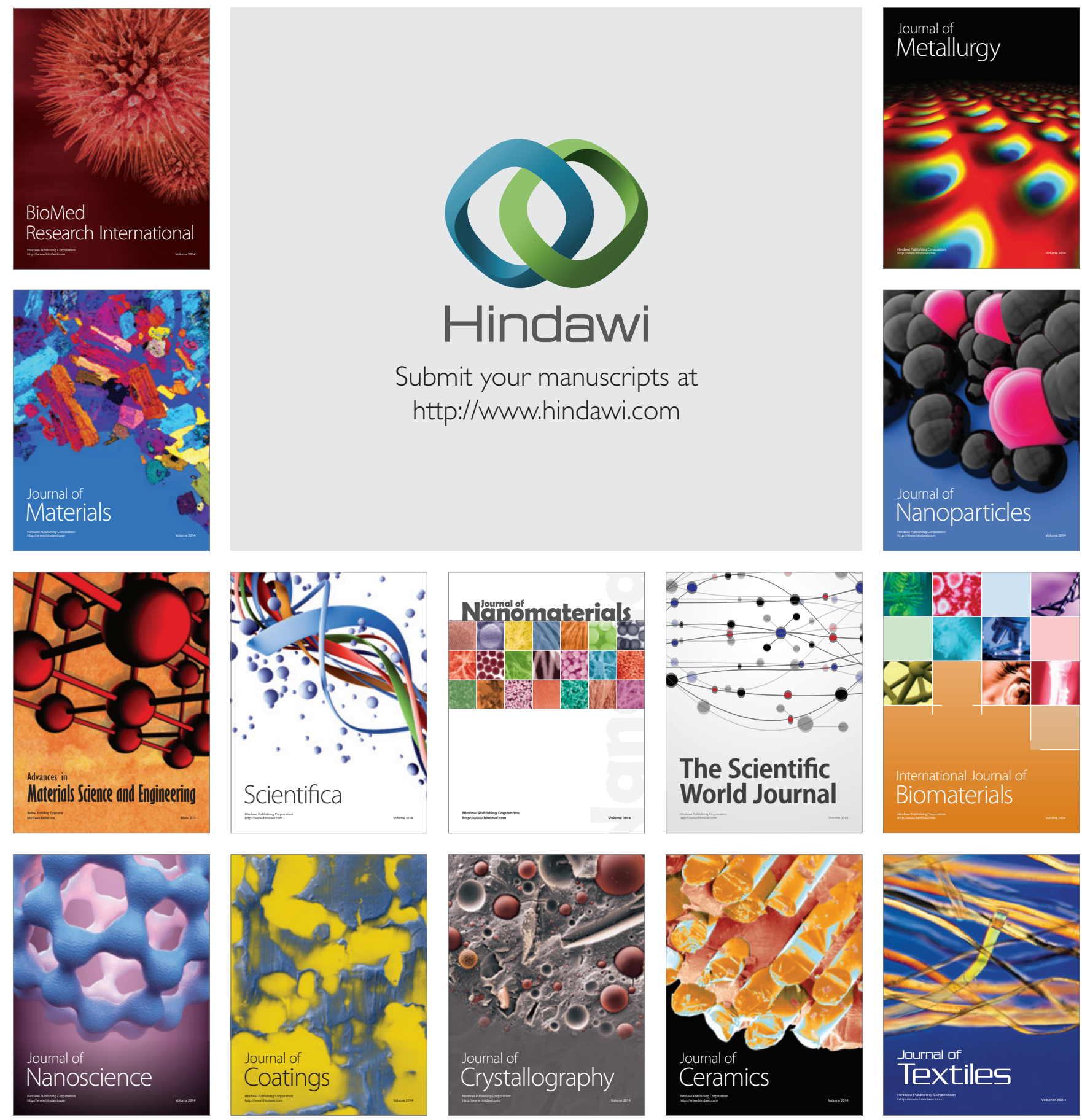